\title{
'The load of diversity': Cognitive load of lessons on biodiversity and classification in the biology textbooks of five different states of India
}

Akhila Machiah, Mohammed Zeeshan, Sruthi Pillai and V V Binoy*

National Institute of Advanced Studies (NIAS), Indian Institute of Science Campus, Bangalore 560012, India

${ }^{*}$ Corresponding author email- vvbinoy@gmail.com

\begin{abstract}
Teaching and learning biodiversity and classification is highly dependent upon visual information and Graphical Representations (GRs) are an essential component of the study materials discussing these topics. However GRs are double edged swords; if used appropriately it reduces the mental effort experienced while learning (cognitive load). Meanwhile, the illustrations loosely connected with the text or complex in its visual properties can hinder the learning significantly. The present study compared the usage of GRs in the lesson on biodiversity and classification given in the IXth standard biology textbooks followed by five different states in India namely Chhattisgarh, Karnataka, Mizoram, Rajasthan, and Telangana and its contribution to the cognitive load. Our result revealed that though these textbooks followed similar contents the properties of the GRs used were noticeably dissimilar. Divergence was also noticed in the way in which the GRs were integrated with the textual information (conceptual integration) and the degree of interaction between such conceptually integrated groups. Influence of such dissimilarity in frequency, form, function, and physical and conceptual integration of GRs on various
\end{abstract}


dimensions of the mental effort required for the comprehension of these vital concepts in environmental science is discussed under the light of the cognitive load theory.

Keywords: Mental effort; biology education; conceptual integration; diagrams; cognitive load theory; Indian schools; environmental education

\section{Introduction}

Being a converging point of information from various limbs of science and social science teaching and learning environmental science / ecology in schools is highly reliant on visual inputs and visualization (Roth \& Bowen, 1999). Students will have to make mental models (Rapp, 2005; Pylyshyn, 2002) of objects ranging from microscopic organisms to complex ecosystems, and events taking seconds to millions of years (e.g. evolution) to comprehend concepts vital in this branch of science. Hence, study materials describing various environmental phenomena, including school biology textbooks are replete with various kinds of Graphical Representations (GR; also known as representation, graphics or illustrations) such as tables, graphs, naturalistic drawings, stylized drawings, equations, flow-chart, etc. (Mayer, 1997; Kintsch, 2004; Sadoski \& Paivio, 2007; Schnotz, 2008). Research has doubtlessly proven that provision of GRs along with the text can ease the formation of schema - units of knowledge (Pass et al., 2003) - since visual representations are a more direct mode of communication than verbal codes and they accentuate cognitive functions (Slough et al., 2010).

GRs help learners to make sense of the information given by reducing cognitive load - 'a multidimensional construct representing the effort that performing a particular task imposes on the learner's cognitive system' (Paas \& van Merriënboer, 1994; Paas et al., 
2003). The Cognitive load could be intrinsic, generated by the inherent mental load attached to the nature of a specific subject and the expertise of the learner, or caused by distraction induced by the external information (extrinsic or ineffective cognitive load). Although, intrinsic and extrinsic cognitive load hamper learning, a third kind, the germane cognitive load, defined as the positive mental effort experienced during the learning process is beneficial to the student. Germane cognitive load encourages the learner to actively engage in conscious cognitive processing of the information received, which in turn encourages the construction and automation of schemas (Pass et al., 2003). Although, GRs help learner in organizing information, improving comprehension and information retention (Carney \& Levin, 2002; Butcher, 2006; Homer \& Plass, 2010) usage of it should be done carefully while designing a textbook. GRs will compete with script, the major medium of communication in the textbooks, for the attention and working memory of the learner, which has a capacity to process simultaneously a limited number of items only. Improperly embedded GRs in the online or offline study materials would will force the reader to ignore textual information by dominating working memory, hinder schema formation and consequent consolidation of it into the long-term memory and retention of the information in an organized and accessible form of knowledge for future usage (Sweller, 1994; 2004; Sweller \& Chandler, 1994).

Functionally, GRs being popularly used in biology textbooks falls under four major categories - 'representational, interpretational, organizational, and decorative' (Slough et al., 2010). The depiction of organisms or concepts using static figures (photographs, stylized diagrams, naturalistic diagrams, etc.) - the representational GR - helps students to perform cognitive operations more efficiently by making the textual information 
available also in the visual form. Enhancing the realistic nature of the representational GR by modulating colour, texture or size increases its acceptability and utility (Keller et al., 2006; Skulmowski \& Rey, 2018). Interpretational GRs simplifies the topic by providing additional information not available in the text as such. For instance, while reading text on human phylogeny, availability of the depictions of various hominids highlighting transformations which occur in various morphological traits during different geological timescales for reference would make learning evolution effortless for the student. Organizational GRs summarize overall information given in a section of the text and bring in the coherence between different concepts discussed in the same or different pages of a chapter (Cook, 2006). Such GRs are a boon for novice learners who may find it difficult to connect pieces of information available into a holistic picture. Flow charts, table, pie diagram, etc., represent organizational GRs. The fourth category, decorative GRs are used primarily to beautify the pages and does not contribute directly to the learning. Generally, decorative GRs are attractively designed; but may not have captions or direct connection or reference to the text. Although the original purpose of decorative GRs is to motivate the learner to use the information given in a page, if not used properly they can be counter-productive by distracting or splitting attention of the learner (Rey, 2012; Scwan, 2017; Korback et al., 2017). Similarly, the presence of a GR loosely integrated or unconnected with the text could also obstruct the learning by inducing the extrinsic cognitive load (Nyachwaya \& Gillaspie, 2016; Mayer, 2005; Mayer et al., 2001). Hence, while designing a textbook quantity and quality of the GRs should be chosen carefully, and integrated with the verbal information in such way that all three kinds of cognitive loads could be managed by the learner without much effort (Paas et al., 2003). 
Amongst divergent topics discussed in the school biology textbooks designing and developing lessons on 'biodiversity and classification' is a challenge for the designers. These lessons aiming to introduce the massive diversity of life forms, ranging from microbes to the mammals and plants and categorizing them based on various traits and evolutionary history is the stepping stone to various vital concepts in ecology such as natural selection, evolution, and conservation. Additionally, the importance of providing quality biodiversity education to the children in a very young age is manifold in the current world of diminishing childhood experience of nature and vanishing global biodiversity (Beery \& Jørgensen, 2018). However, designing lessons on this topic for a modern textbook which follows webpage format is a herculean task since the number of figures integrated into each page should be enough to communicate the concept but at the same time, they should not escalate the extrinsic cognitive load. In this context, it should also be noted that textbooks are one of the main source of curricular information and content provider to the teachers, and a first-hand knowledge resource for students in science classrooms (McTigue \& Slough, 2010). Moreover, in most of the developing nations, dependency on textbooks by both teachers and students are paramount since both of them seldom get the chance to use tools of free choice learning and evaluation of the student is highly dependent upon the syllabus based examinations. Hence a textbook chapter on any topic in ecology, especially biodiversity and classification, should blend text and figures in such ways that the learner feels the minimum mental effort, use both verbal and visual contents provided and experience the joy of learning (Slough et al., 2010). 
India is a nation well known for its cultural and language diversity, which reflects also in the biology textbooks followed by various states of this geographically large nation. Although, National Council for Education Research and Training (NCERT), a Central government institution, develops textbooks for the standards I to XII in three languages (Hindi, English and Urdu), many states follow science textbooks designed by their own State Councils for Education Research and Teaching (SCERT). The content of these textbooks written in vernacular languages is more or less similar to that of NCERT; however, they vary significantly in color, design, type and integration of the GRs used. Although both central and state governments are actively trying to popularize Information Communication Technology (ICT) based science education, for majority of the schools in rural regions of India, teaching and learning biology are highly dependent on these textbooks. It should also be noted that India is losing its rich resource of biodiversity very quickly (Padma, 2013). Sensitizing children at a very young age itself about the need for protecting other forms of life coexisting with them can catalyze the development of environmental pro behaviour (Binoy et al., 2017; Radhakrishna et al., 2014). Hence tracing out the factors hindering comprehension of vital topics in environmental science such as biodiversity, classification, evolution etc. while learning from textbook, by generating extrinsic and intrinsic cognitive load could help designers to come up with more refined study materials and pedagogies. Unfortunately, no research analyzing the cognitive load imparted by the biology textbooks being used by thousands of children from various states of India, is available in the literature till date. The present study explored various dimensions of GRs and its integration with the textual information in the lesson on 'Biodiversity and Classification' in the IX ${ }^{\text {th }}$ standard biology textbooks followed by five different states of India under the light of cognitive load theory. 


\section{Methodology}

\section{Textbooks}

The present study focused on ninth grade biology textbooks followed by five different states of India, Chhattisgarh, Karnataka, Mizoram, Rajasthan, and Telangana during academic year 2015-2016 to 2018-2019. In the academic year 2015- 2016 all focal states were following the textbooks developed by the respective SCERTs, except Rajasthan which taught NCERT textbook. In 2016 - 2017 Karnataka also moved to NCERT textbook, but Rajasthan adopted a new one (Rajasthan New; RN). The NCERT textbook used by Rajasthan during the year 2015-16 and Karnataka during the year 2016-17 is referred to as $\mathrm{RO} / \mathrm{KN}$ (Rajasthan Old/Karnataka New), here after as both textbooks are same. The textbook being used by Karnataka in $2015-16$ is referred to as KO (Karnataka Old).

The chapter on 'biodiversity and classification, a topic common to all the focal textbooks was chosen for the analysis. Due to the nature of the topic discussed these chapters had large number of images and diagrams of diverse kinds of plants, animals and microbial organisms. Designing this chapter is a challenge since number, style, form etc. of the GRs have to be chosen in such a way that the students should not mix up the names and figures of the diverse kinds of organisms, many of which are totally unfamiliar to the learners. Furthermore, in order to reduce cognitive load and help children to understand the concept of classification of living things, various kinds of GRs other than images and diagrams were also found being utilized in this chapter.

\section{Sampling and Coding}

The chapter on biodiversity and classification was distributed on 18-28 pages in the focal 
textbooks. GRs given in each page of the chapter were coded and analyzed using Graphical Analysis Protocol (GAP Slough et al., 2010) and modifications suggested by Nyachwaya and Gillaspie (2016). First, different type of GRs, photographs, naturalistic drawing, stylized drawing, picture glossary, scale diagram, flowchart (both cycle and sequence) cutaway/cross section, maps, tables, graphs enlargement and hybrids (combination of two or more types of GRs) were counted and its nature (color or black and white) were recorded. Physical integration was coded direct, proximal, facing, distal or unconnected based on the proximity to the text associated. 'Direct' GRs were positioned adjacent to the text associated, 'proximal' on the same page and in the case of 'facing', text and graphics would be positioned on the facing pages. A GR is considered 'distal' if the reader is required to turn pages and those without any connection with the text were marked 'unconnected'. The indexical referencing, directing the reader to refer figure is essential to bridge text with GR while reading the textbook. The citation of the figures in the text was coded as follows: unindexed, indexed on same page, indexed on different page and wrongly indexed. Along with proper citation, provision of captions detailing GRs can reduce confusion and increase comprehension. The illustrations without any legend were recoded as 'no caption', while GRs with captions were segregated into 3 categories: identifies, detailed description and engaging based on the details given.

All GRs present in the focal chapter were also segregated into four categories, representational, decorative, organizational and interpretational based on the function they performed. Generally, each GR given in a chapter is connected to a specific segment of the script, another GR, or both. The reader is expected to connect these elements to comprehend the concept described. The conceptual integration of GRs with text - the need 
for reading text or referring other representation in order to understand the information encoded in an image - was also quantified. If a GR is linked only with a section of the text or another figure it is attributed a Conceptual Integration group (CIg) size value $2 \mathrm{G}$. The CIg value reaches 3, when one GR is bridged with two segments of the textual information, a couple of other visual representations or a pair consisting of an image and a unit of text. In many contexts, a CIG won't continue as an independent entity; it may be further connected with one or many similar groups. Such sets of interacting CIGs are known as Conceptually Interacting group (CIn). The CIn value, the degree of interaction between various CIGs, was quantified following the methodology used for coding conceptual integration groups (Nyachwaya \& Gillaspie, 2016).

Each chapter was analyzed by three coders independently and their results were compiled in to a single data set. The value obtained for each parameter studied was divided with the total number of pages present in the focal chapter and the result was further transformed to $\log _{10}$ for a better visual representation.

\section{Results}

\section{Number of GRs per page and form}

Although content of the chapter on biodiversity and classification was almost similar in all focal textbooks, design of the pages and types of GRs provided were not consistent. Our study revealed that this chapter varied in the average number of GRs present per page across the textbook studied. Telangana and KO had maximum two GRs per page, while $\mathrm{RO} / \mathrm{KN}$ was with more than 4, and Mizoram occupied an intermediate position with an average of 3 representations per page. The new textbook of Rajasthan (RN) was not 
different from its previous version $(\mathrm{RO} / \mathrm{KN})$ as far as the number of GRs present per page is concerned, but when Karnataka moved from $\mathrm{KO}$ to $\mathrm{RO} / \mathrm{KN}$ the GRs per page increased from 2 to 4.8 (Fig. 1). It is a well-known fact that multicolored photographs and natural diagrams are superior over their black and white counterparts in communicating ideas, due to the realistic experience provided to the reader (Yasar \& Seremet, 2007). However, textbooks followed by both Mizoram and Chhattisgarh states were without any colored GRs, while Telangana textbook used only colored ones (Fig 2). Chhattisgarh, Mizoram $\mathrm{RO} / \mathrm{KN}, \mathrm{RN}$ and $\mathrm{KO}$ had significantly lesser number of photographs in comparison to the Telangana and KN.

The natural diagrams followed a similar trend, but $\mathrm{RO} / \mathrm{KN}$ and $\mathrm{RN}$ were exceptions and contained more GRs of this category. Stylized diagram was the most preferred form of illustration by the textbook designers of all the five-focal state. However, though the provision of a scale with the GR could have helped student to visualize a more realistic picture of the object represented, only Telangana textbook contained any scaled diagrams. May be due to the nature of the topic discussed, the chapter on biodiversity and classification contained no cyclic flow charts. However, sequential flow charts were used in all focal textbooks for elaborating classification. Interestingly, KO did not have any sequential flow charts and nor did RN. The number of tables used in all the five textbooks studied were very low and there were no tables present in the $\mathrm{RN}$ and $\mathrm{RO} / \mathrm{KN}$. Chhattisgarh text book has some tables in the beginning of the chapter, which were not the part of the main text, and hence was not considered while analysis. Hybrids - an amalgamation of more than one type of GR - was present only in the Mizoram, RN and Telangana textbook, nonetheless the quantity was very few (Fig. 2). 


\section{Label and captions}

It is undisputed that proper labelling, captioning and referencing is necessary for bridging GRs with textual information and comprehension. Inadequate referencing would end up in the escalation of cognitive load and underutilization of GRs (Slough et al., 2010). Majority of the representations provided in the chapter on the biodiversity and classification in all five textbooks studied were without proper labelling. Amusingly no GRs in this chapter of Telangana textbook was found labelled. In comparison to $\mathrm{RO} / \mathrm{KN}$, RN has increased the number of labelled GRs (Fig. 3). Most of the captions available with GRs were either single word or line in nature, across the textbook studied and performed mainly the function of identifying the target (Fig. 4). Hence, we did not used the category ‘extended caption' suggested by Nyachwaya and Gillaspie (2016). Our analysis revealed that Telangana and Mizoram contained more GRs without any caption or legend in comparison to the other textbooks, but $\mathrm{RN}$ had no uncaptioned illustrations.

\section{Physical integration and referencing}

Positioning GR in the vicinity of the textual information associated with it and guiding reader to refer it is a key for maximizing the benefit of illustrations provided on a page. Proximal GRs got the first position in the frequency of usage and 'direct' and 'facing' decorated the second and third positions respectively in all textbooks. Figures, requiring turning of the page for getting textual information or not having any link to the verbal information (unconnected) were also not rare. A detailed analysis revealed that direct GRs were menial in number in $\mathrm{RO} / \mathrm{KN}$, while $\mathrm{RN}$ was completely lacking this form of physical integration (Fig. 5). In all focal textbooks on an average, half of GRs were not properly cited (Fig. 6) and Chhattisgarh, $\mathrm{KO}$ and $\mathrm{RN}$ had no referencing at all. In $\mathrm{RO} / \mathrm{KN}$ 
many figures were indexed on a different page and wrongly indexed figures were noticed in Telangana.

\section{Function}

Our result revealed that majority of the figures provided in the focal chapter in all five text books were representational in nature, followed by the organizational ones (Fig. 7). Surprisingly RN contained no other kinds of GRs except the representational and KO had a lesser number of organizational figures. No interpretational GRs were found in the Chhattisgarh, $\mathrm{RO} / \mathrm{KN}$ and $\mathrm{RN}$ textbooks and the appearance of this form of illustration was less frequent in other textbooks. Interestingly $\mathrm{KO}$ and $\mathrm{RN}$ were found to be using literally no decorative graphical representations though the presence of it was noted in other textbooks.

\section{Conceptual integration and interaction}

All the five text books analyzed for the size of conceptual integration (CIg; Fig. 8) and conceptual interaction (CIn; Fig. 9) groups revealed a majority for the sets of size $2 \mathrm{G}$ and 3G. However, many CIgs of size $4 \mathrm{G}$ and above were present in Chhattisgarh, KO, Mizoram and $\mathrm{RN}$. The $\mathrm{RO} / \mathrm{KN}$ and Chhattisgarh text books restricted the size of $\mathrm{CIn}$ to $3 \mathrm{G}$, while

KO contained very few such groups with a value lesser this. In Mizoram, KO and Telangana many CIns exceeding the size $4 \mathrm{G}$ were noticed.

\section{Discussion}

Being a subject describing the phenomena of life at various levels of complexity, ranging from single cellular microbes to ecosystems spreading over thousands of kilometers, both 
teaching and learning of environmental science in general and biodiversity and classification in particular is highly dependent upon visual inputs. Hence, biology textbooks describing such topics use a wide range of GRs for assisting students to reduce the cognitive load and enhance schema formation (Seufert, 2003; Seufert \& Brünken, 2006). The present study revealed that high school biology textbooks used in various states of India is a blend of verbal and visual representations. Although, contents of the chapter on biodiversity and classification were nearly same, the format of pages and the number and nature of GRs used were strikingly dissimilar. For instance, Telangana and KO textbooks contained only two figures on each page while $\mathrm{RO} / \mathrm{KN}$ had more than four images. Although, GRs would help in reducing the intrinsic cognitive load, they would also compete with the textual information for the attention and working memory of the student and will in turn generate extrinsic cognitive load even if the illustrations and topic discussed are simple in nature (Cook, 2006). According to Corradi et al. (2014) presence of more than two GRs on a page would result in increased extrinsic cognitive load and reduces the chance of expression of germane cognitive load. Furthermore, pages packed with GRs will heighten the learning difficulty for the students without any prior experience with the topic. Hence, there is a very high chance that students of Mizoram, Rajasthan and Karnataka (using $\mathrm{RO} / \mathrm{KN}$ ) may be experiencing more cognitive load due to the crowding of GRs. Unfortunately, while revising the textbook Rajasthan continued the pattern present in the previous version $(\mathrm{RO} / \mathrm{KN})$ and didn't reduced the frequency of GRs per page in their new textbook (RN). However, while discussing a topic such as biodiversity and classification, which highlights morphological features of diverse living things, enhanced density of images on a page could lead students to confusion. Furthermore, in India due to the noticeable digital and economical divide very few 
students from rural and marginalized areas get prior experience with the topics given in their curriculum. Hence, Rajasthan, Mizoram and Karnataka states should consider optimizing the number of GRs present on each page in the forthcoming editions of the $\mathrm{IX}^{\text {th }}$ standard biology textbooks.

Amongst various kinds of illustrations, photographs especially color photographs offer the most realistic representation of the organisms to the learner (Yasar \& Mehmet, 2007). Availability of a diagrammatic representation matching real image of the organism described would be useful in reducing the intrinsic cognitive load in the absence of photographs. In general, stylized diagrams - symbolic illustrations and depictions using outlines - was the most popular form of GRs used across the textbooks (Slough et al.,2010). Chhattisgarh, Mizoram and RO/KN textbooks were with lesser number of photographs and first two were devoid of any color photos or diagrams. Interestingly the new Rajasthan textbook (RN) significantly increased the number of colored diagrams and photographs. However, the new Karnataka textbook (RO/KN) followed an opposite trend and increased the number of black and white images and reduced the quantity of photographs. In this context, it should be noted that black and white photographs and natural diagrams given in the textbooks could makes it less attractive to the students (Yasar \& Mehmet, 2007). Another important observation was the unavailability of the scale with GRs for reference in majority of the textbooks analyzed. Displaying photographs or stylized diagrams of unfamiliar organisms divergent in body size on the same or facing pages of the textbook without the scale can lead to the development of misconceptions amongst the students. 
Labelling and captioning each GR given on a page and actively guiding the learner to extend attention to it while reading the text is a key for integrated processing of verbal and representational inputs (Peeck, 1993). Availability of captions and labels reduce the undesirable extraneous cognitive load by releasing the pressure on working memory, and upturn germane cognitive load by promoting active processing of the information existing in the GR. According to Paas and van Merrienboer (1993) students learn more from properly labelled representations and such GRs are the signatures of a good instructional design. The importance of captions, labels and referencing manifold when a page of the textbook display more than one image and concepts (Plass et al. 2009). Although on an average, each page of the focal chapter contained more than two GRs across the five biology textbooks analyzed, most of them were not labelled properly. Moreover, very few GRs were with extended captions; a single word or a very brief sentence was the rule wherever it was present. Noticeably in Telangana textbook, not even a single GR was labelled. The designers could argue that labelling and providing captions to each and every GR given in a chapter on biodiversity and classification is difficult and would increase the size of the textbook enormously. However, while learning a topic such as the morphological or behavioural features of a microbe or an organism inhabiting in an ecosystem unfamiliar to the student availability of labels and proper description eases the comprehension. Conversely, GRs without caption or labels could be perceived as intimidating because all students would not be able understand the representations on their own and connect it with the text (Holliday, 1976; Holliday \& Benson, 1991).

Along with adequate labelling and provision of captions appropriate positioning and indexical referring of GRs are also essential to harness the benefits of it (Peeck, 1993; 
Slough et al., 2010). Eye tracking studies revealed that while reading textbook students continuously switch between verbal and graphical information and continuity of the learning process will be disturbed if these two kinds of information are placed distally (Korback et al., 2017; Mayer, 2001, McTigue \& Slough, 2010). Hence in the view of experts it is always better to position GRs adjacent to the text associated (direct) or on the same page (proximal) since turning the page for getting verbal information associated with the figure (distal) could spit attention of the reader (de Jong, 2010). Majority of the focal textbooks we studied kept GRs in the proximal position and $\mathrm{RO} / \mathrm{KN}$ and $\mathrm{RN}$ were with exceptionally low number of direct GRs. Some unconnected GRs were also noticed in all textbooks except Telangana, which should be either linked to the verbal information or removed in the forthcoming versions. Inappropriate handling of citation was observed across the textbooks considered under the present investigation. Chhattisgarh and KO textbooks did not have any direction to refer figures while reading while RO had high number of references on a different page. We noticed some incorrect indexing, referring a wrong GR, in the Telangana textbook. This observations raise serious concern, while learning chapter, which illustrates the diversity of living thing and displays various GRs on every single page, it is undoubted that neglecting referencing, wrong indexing or providing reference on a different page could elevate extrinsic cognitive load and confuse the students(Slough et al., 2010).

May be due to the nature of the topic discussed, the categorization of the GRs based on the function they performed revealed a strong bias towards 'representational' (more than 80\%) in all textbooks. Although this category of GRs could help student to visualize the organisms or concepts described in the text, organizational GRs, which stresses active 
processing of the figures by the reader was less frequent in the focal chapters. While learning a vital concept such as classification availability of organizational graphics (which aids convergence of various information) and interpretational GRs (which facilitates additional information) can increase germane cognitive load and active utilization of GRs (Slough et al. 2010). Interestingly, all focal textbooks contained many decorative GRs, though KO stood out of the group with no such figure. In a chapter on biodiversity and classification that requires processing of large number of representations while learning, presence of additional figures aiming only beautification can magnify the already existing extrinsic cognitive load. Decorative GRs have high potential for generating distraction hamper learning process, hence in a textbook such illustrations should be used in unavoidable circumstances only (Slough et al., 2010).

According to Rieber (1990) students will be able to grasp a lesson more effectively if the information is presented as 'chunks- the smaller subsets of textual and graphical sequences'. However, in many contexts GRs present in a chapter and the text associated with it may not follow a one to one relationship; reader will have to integrate the information present in diverse chunks and actively consider the interactions between them to generate a holistic picture of the topic discussed. The number of such chunks needs to be connected while learning is positively correlated with the mental effort. The more the size and number of conceptually integrating and interacting groups in a chapter the more will be the intrinsic cognitive load (Nyachwaya \& Gillaspie, 2016). The Comparison of the average number of conceptually integrated (CIg) and interacting (CIn) groups present in the chapter on biodiversity and classification revealed that Chhattisgarh, Mizoram, $\mathrm{KO}$ and $\mathrm{RN}$ textbook contained many such group with a value 
higher than 4G. Processing such information distributed over various chunks would demand more working memory and spiking of the intrinsic and extrinsic cognitive load. Such a demand for higher level of mental effort may persuade students, especially those who lacks previous experience with the topic, to skip the GRs while learning or to leave even the whole lesson unattended (Corrandi et al., 2014; Sombatteera \& Kalyuga, 2012). Hence, teachers should be made aware of this issue and proper training and additional teaching material should be given to reduce the impact of higher size of conceptually integrated (CIg) and interacting (CIn) groups on the learning ability of the students.

Understanding cognitive load generated by the textual and graphical contents of the textbooks and strategies used by the children to cope with it has wider implications in enhancing the quality of education. If designers of the textbook could make use of the knowledge of GR - text integration at physical and conceptual level and come up with strategies to reduce intrinsic and extraneous cognitive loads and increase germane cognitive load learning biology will become fun and effortless (Slough et al., 2010). Additionally, making teachers familiar with the concept of germane cognitive load, its importance in enhancing the quality of education, and training them to find the sections of a chapter is with high levels of intrinsic and extrinsic cognitive load could help them to give more emphasis to such topics while teaching it in the classroom. The developers of educational websites and learning apps are also benefited from the studies focusing three dimensions of the cognitive load since such data could help them to design contents with lesser constrain on working memory. Hence, future studies analyzing neurophysiological and psychological underpinning of the mitigation of cognitive load while integrating textual and visual information, using modern tools of neuroscience would help educators 
to design curriculum and pedagogy for students varying in their personality traits, cognitive capacity and experience with various subjects.

\section{Acknowledgment}

We are grateful to the Connected Learning Initiative (CLIx), Tata Institute of Social Science for the financial assistance which made this study possible.

\section{References}

Binoy, V. V., Radhakrishna, S., \& Kurup, A. (2017). Bridging Educational Institutions for a Citizen Science Project: A Case Study from Malappuram District, Kerala, India. In Bridging the Communication Gap in Science and Technology (pp. 269-277). Springer, Singapore.

Beery, T., \& Jørgensen, K. A. (2018). Children in nature: sensory engagement and the experience of biodiversity. Environ. Edu. Res., 24(1), 13-25.

Padma, T. V. (2013). India faces uphill battle on biodiversity. Nature, 504(7479), 200.

Butcher K. R., (2006), Learning from text with diagrams: promoting mental model development and inference generation, J. Educ. Psychol., 98(1), 182-197.

Carney R. N. \& Levin J. R., (2002), Pictorial illustrations still improve students' learning from text. Educ. Psychol. Rev., 14(1), 5-26. 
Cook M. P. (2006), Visual representations in science education: the influence of prior knowledge and cognitive load theory on instructional design principles. Sci. Educ., 90(6), 1073-1091.

Corradi D. M. J., Elen J., Schraepen B. \& Clarebout G., (2014), Understanding possibilities and limitations of abstract chemical representations for achieving conceptual understanding. Int. J. Sci. Educ., 36(5), 715-734.

de Jong, T. (2010). Cognitive load theory, educational research, and instructional design: some food for thought. Instr. Sci. 38, 105-134.

Holliday, W. G. (1976). Teaching verbal chains using flow diagrams and texts. Audio-Vis. Comm. Rev., 24, 63-78.

Holliday, W. G., \& Benson, G. (1991). Enhancing learning using questions adjunct to science charts. J. Res. Sci. Teach., 28(1), 99-108.

Homer B. D. \& Plass J. L., (2010). Expertise reversal for iconic representations in science visualizations. Inst. Sci., 38, 259-276.

Keller, T., Gerjets, P., Scheiter, K., \& Garsoffky, B. (2006). Information visualizations for knowledge acquisition: The impact of dimensionality and color coding. Computers Hum. Behav., 22(1), 43-65.

Kintsch W., (2004). The construction-integration model of text comprehension and its implications for instruction, in Ruddell R. B. and Unrau N. J. (ed.), Theoretical models and processes of reading, Newark, NJ: IRA, pp. 1270-1328. 
Korbach, A., Brünken, R., \& Park, B. (2017). Differentiating different types of cognitive load: A comparison of different measures. Edu. Psy. Rev., 1-27.

Mayer R. E., (1997). Multimedia learning: are we asking the right questions? Educ. Psychol., 32(1), 1-19.

Mayer R. E., (2005). Principles for Reducing Extraneous Processing in Multimedia Learning: Coherence, Signaling, Redundancy, Spatial Contiguity and Temporal Contiguity Principles, in Mayer R. E. (ed.) The Cambridge Handbook of Multimedia Learning, Cambridge: Cambridge University Press, pp. 182-200

Mayer R. E., Heiser J. \& Lonn S., (2001). Cognitive constraints on multimedia learning: when presenting more material results in less understanding. J. Educ. Psychol., 93(1), $187-198$

Mayer, R. E. (2001). Multimedia learning. Cambridge: Cambridge University Press.

McTigue E. M. \& Slough S., (2010). Student-accessible science texts: elements of design Read. Psychol., 31, 213-227

Nyachwaya, J. M., \& Gillaspie, M. (2016). Features of representations in general chemistry textbooks: a peek through the lens of the cognitive load theory. Chem. Edu. Res. Pract. 17(1), 58-71.

Paas, F., \& van Merriënboer, J. J. G. (1993). The efficiency of instructional conditions: An approach to combine mental effort and performance measures. Hum. Fact., 35, 737-743.

Paas, F., \& van Merriënboer, J. J. G. (1994a). Instructional control of cogni- tive load in the training of complex cognitive tasks. Edu. Psyc. Rev., 6, 51-71. 
Paas, F., Tuovinen, J. E., Tabbers, H., \& Van Gerven, P. W. (2003). Cognitive load measurement as a means to advance cognitive load theory. Edu. Psychologist, 38(1), 6371.

Peeck, J. (1993). Increasing picture effects in learning from illustrated text. Learning and Instruction, 3, 227-238.

Plass, J. L., Homer, B. D., \& Hayward, E. O. (2009). Design factors for educationally effective animations and simulations. J. Comput. High. Edu., 21(1), 31-61.

Pylyshyn, Z. W. (2002). Mental imagery: In search of a theory. Behav. Brain Sci., 25, $157-238$.

Radhakrishna, S., Binoy, V. V., \& Kurup, A. (2014). The culture of environmental education: insights from a citizen science experiment in India. Curr. Sci., 107(2), 176178.

Rapp, D. N. (2005). Mental models: Theoretical issues for visualizations in science education. In Gilbert, J. K. (Ed.), Visualization in Science Education (pp. 43-60). Netherlands: Springer.

Rey, G. D. (2012). A review of research and a meta-analysis of the seductive detail effect. Edu. Res. Rev. 7(3), 216-237.

Rieber, L. P. (1990). Using computer animated graphics in science instruction with children. J. Edu. Psychol. 82(1), 135-140. 
Roth, W. M., \& Bowen, G. M. (1999). Complexities of graphical representations during ecology lectures: An analysis rooted in semiotics and hermeneutic phenomenology. Learning and Instruction, 9(3), 235-255.

Sadoski M. \& Paivio A., (2007). Toward a unified theory of reading, Sci. Stud. Read., 1, $337-356$.

Schnotz W., (2008). Why multimedia learning is not always helpful, in Rouet J., Lowe R. and Schnotz W. (ed.) Understanding multimedia documents, New York, NY: Springer, pp. $17-42$.

Schwan, S. (2017). Digital pictures, videos, and beyond: Knowledge acquisition with realistic images. in The Psychology of Digital Learning (pp. 41-59). Springer, Cham.

Seufert, T., \& Brünken, R. (2006). Cognitive load and the format of instructional aids for coherence formation. Applied Cognitive Psychology: The Official Journal of the Society for Applied Research in Memory and Cognition, 20(3), 321-331.

Seufert T., (2003). Supporting coherence formation in learning from multiple representations. Learn. Instr., 13, 227-237.

Skulmowski, A., \& Rey, G. D. (2018). Realistic details in visualizations require color cues to foster retention. Computers. Edu..

Slough S. W., McTigue E. M., Kim S. \& Jennings S. K., (2010). Science textbooks' use of graphical representation: a descriptive analysis of four sixth grade science texts. Read. Psychol. 31, 301-325. 
Sombatteera, S. \& Kalyuga, S., (2012). When dual sensory mode with limited text presentation enhance learning. Procedia-Soc. Behav. Sci. 69, 2022-2026.

Subramaniam, K. (2014). Student teachers' conceptions of teaching biology. J. Biol. Edu. 48(2), 91-97.

Sweller J. \& Chandler P., (1994). Why some material is difficult to learn. Cognition Instruct., 12(3), 185-233.

Sweller J., (1994). Cognitive Load Theory, Learning Difficulty and Instructional Design, Learn. Instr., 4(4), 295-312.

Sweller J., (2004). Instructional design consequences of an analogy between evolution by natural selection and human cognitive architecture. Instr. Sci., 32, 9-31.

Yasar, O. \& Seremet, M. (2007). A comparative analysis regarding pictures included in secondary school geography textbooks taught in Turkey. Int. Res. Geograph. Envt. Edu., 16(2), 157-188. 
Figure 1 Average number of GRs present per page of the chapter on biodiversity and classification given in the $\mathrm{IX}^{\text {th }}$ standard biology textbook followed by five different states of India, Chhattisgarh, Mizoram, Telangana, Rajasthan and Karnataka.

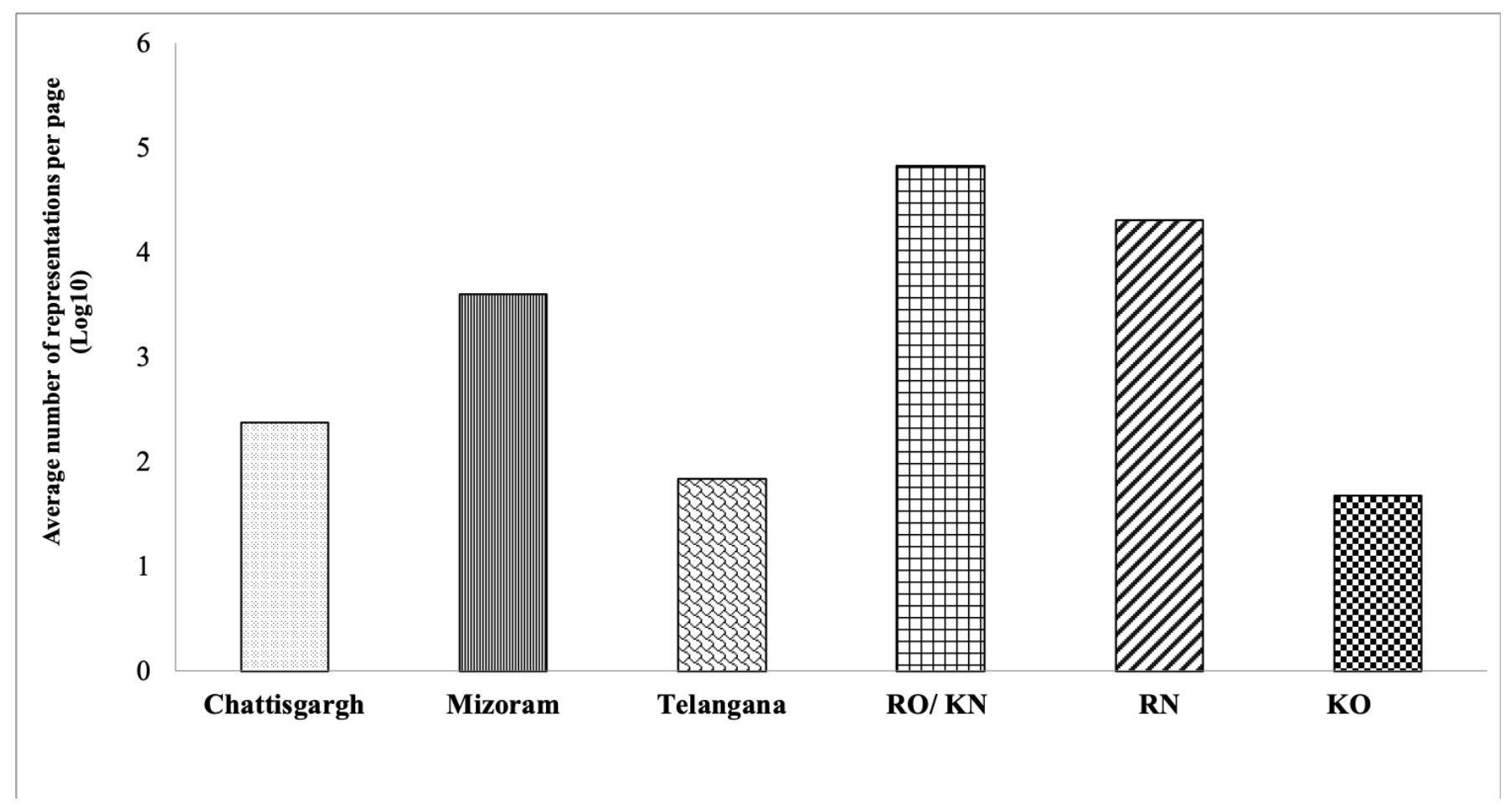




\section{Figure 2}

Forms of GRs present in the chapter on biodiversity and classification given in the IX ${ }^{\text {th }}$ standard biology textbook followed by five different states of India, Chhattisgarh, Mizoram, Telangana, Rajasthan and Karnataka.

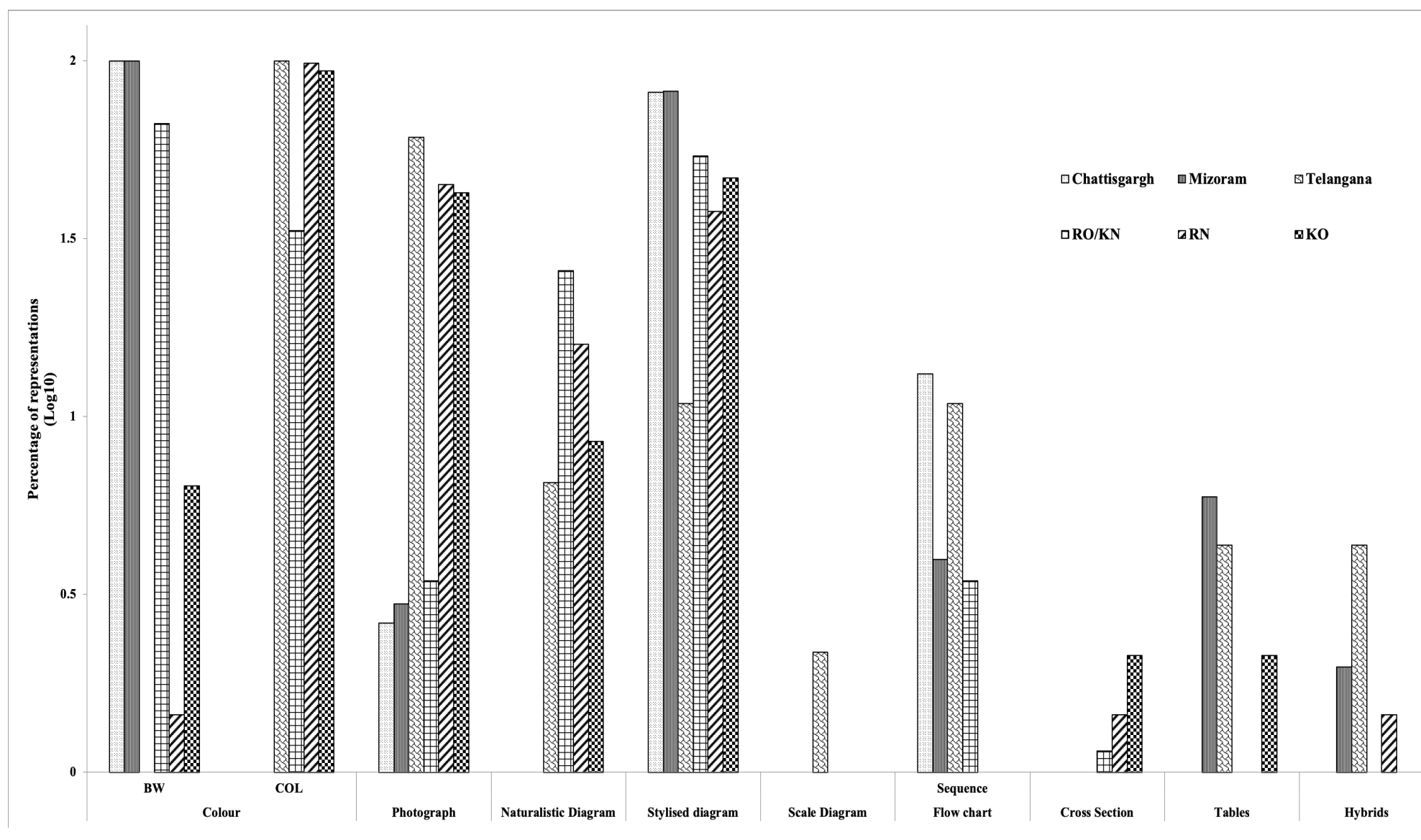


Figure 3 Labelling of GRs present in the chapter on biodiversity and classification given in the IX ${ }^{\text {th }}$ standard biology textbook followed by five different states of India, Chhattisgarh, Mizoram, Telangana, Rajasthan and Karnataka.

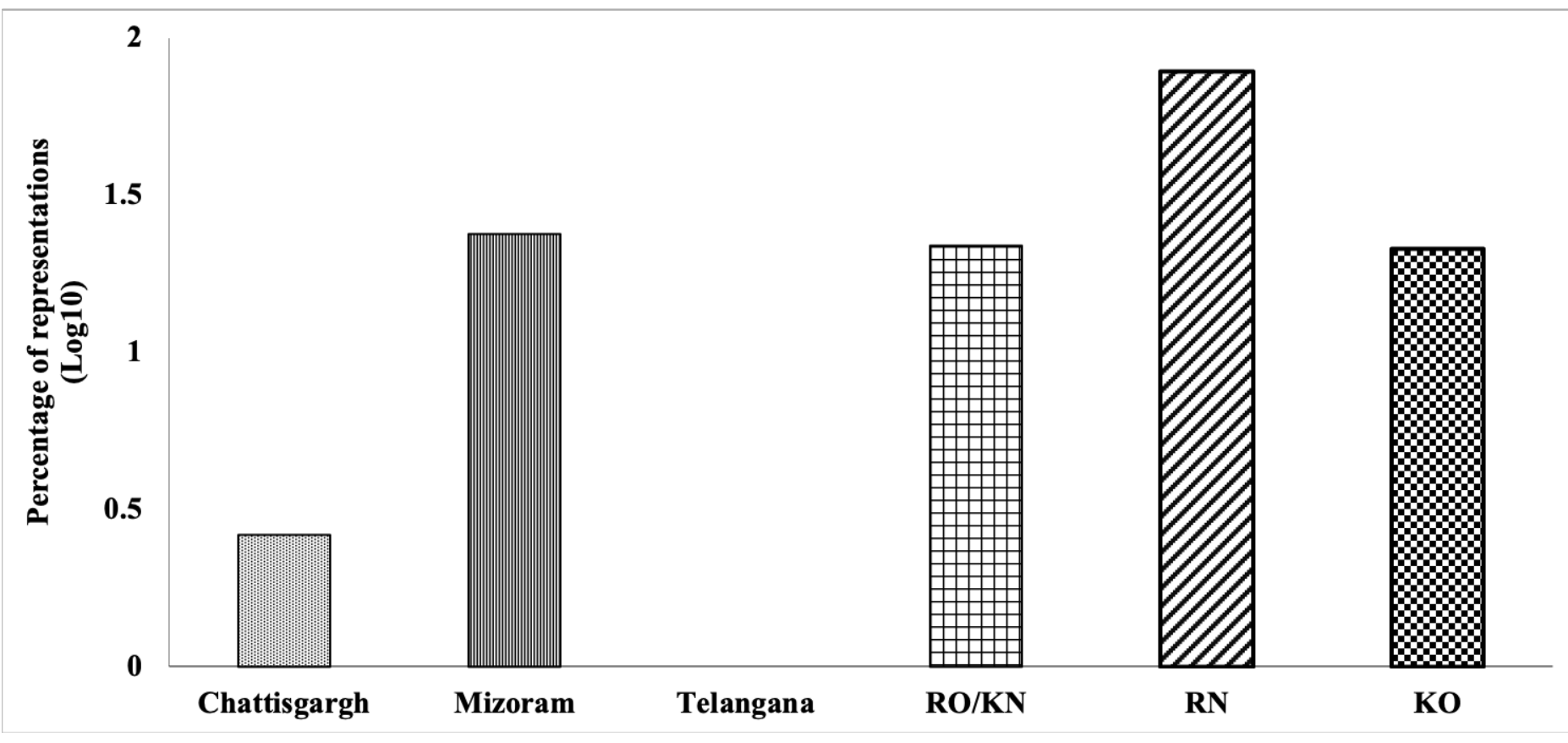


Figure 4 GRs with captions present in the chapter on biodiversity and classification given in the $\mathrm{IX}^{\text {th }}$ standard biology textbook followed by five different states of India, Chhattisgarh, Mizoram, Telangana, Rajasthan and Karnataka.

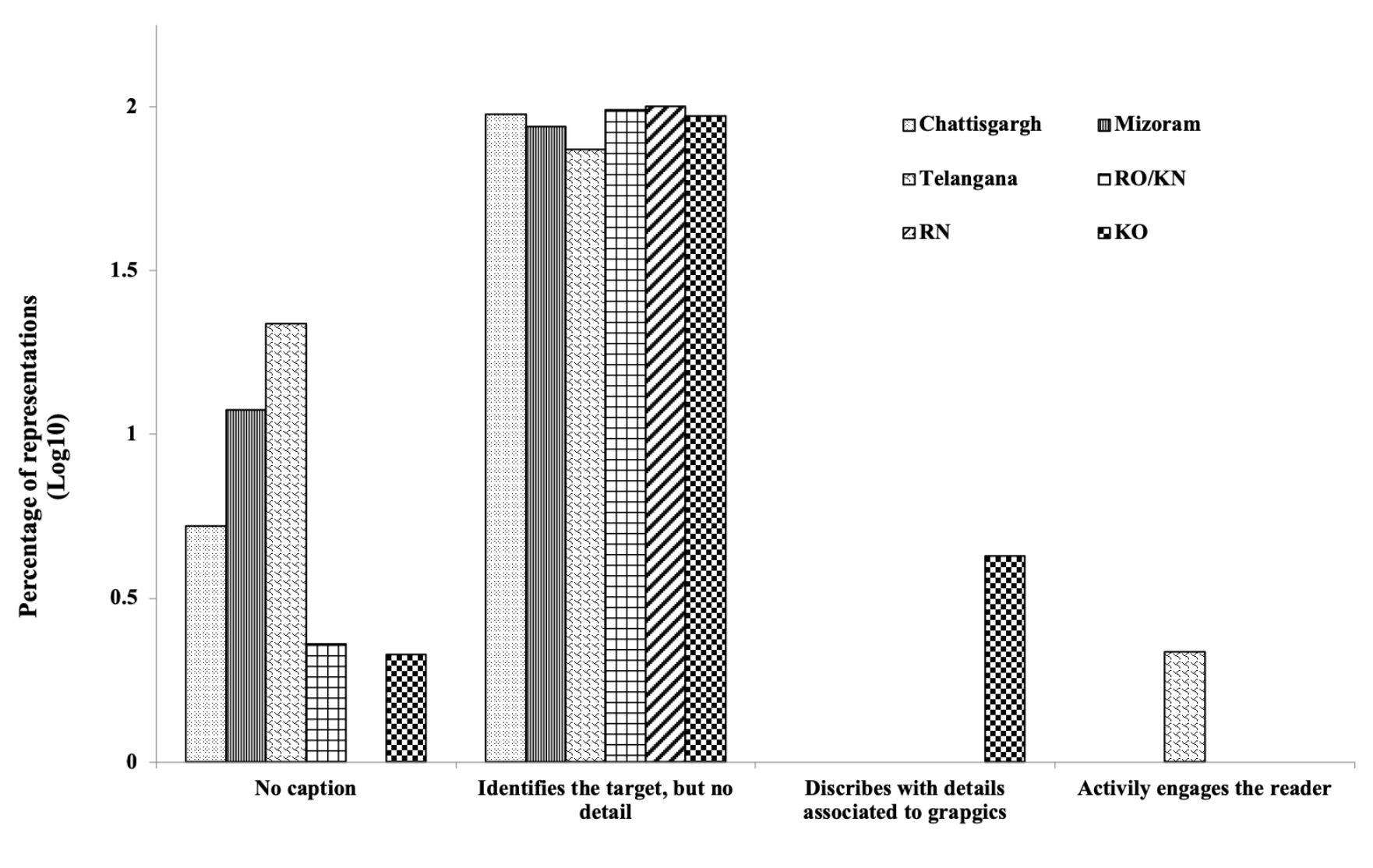


Figure 5 Physical integration of GRs present in the chapter on biodiversity and classification given in the IX ${ }^{\text {th }}$ standard biology textbook followed by five different states of India, Chhattisgarh, Mizoram, Telangana, Rajasthan and Karnataka.

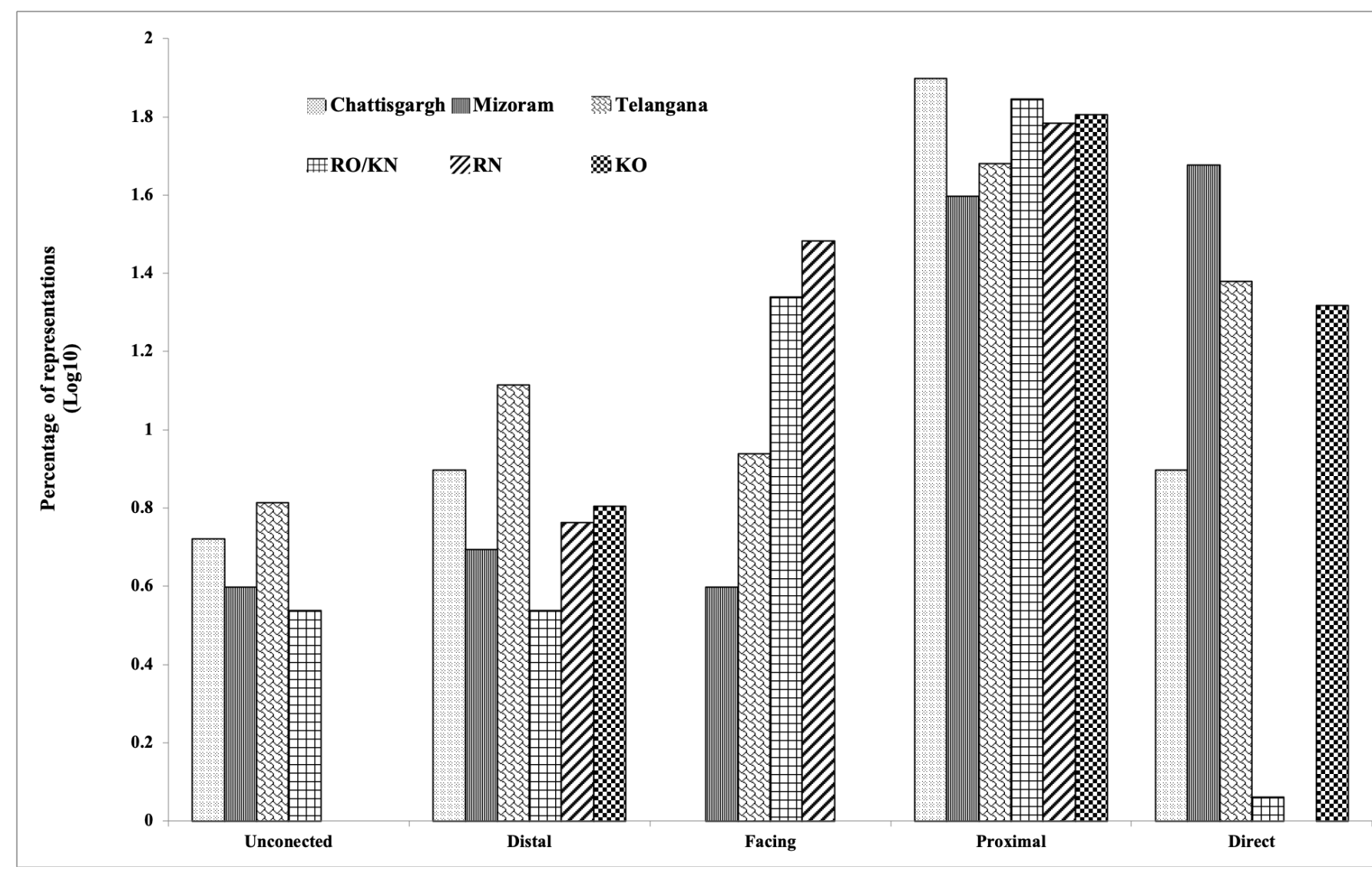


Figure 6 Indexing of GRs present in the chapter on biodiversity and classification given in the IX ${ }^{\text {th }}$ standard biology textbook followed by five different states of India, Chhattisgarh, Mizoram, Telangana, Rajasthan and Karnataka.

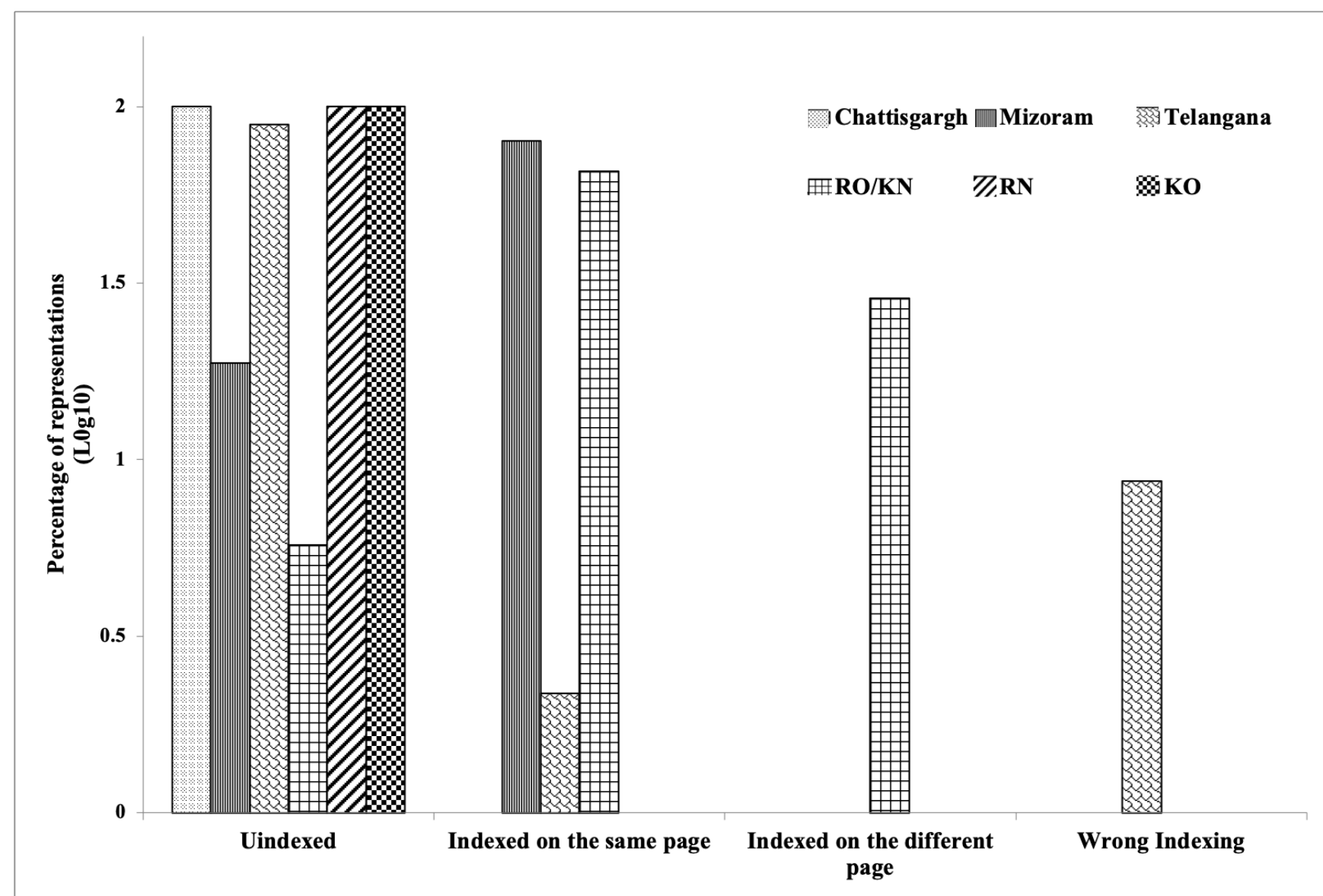


Figure 7 Function of the GRs present in the chapter on biodiversity and classification given in the IX ${ }^{\text {th }}$ standard biology textbook followed by five different states of India, Chhattisgarh, Mizoram, Telangana, Rajasthan and Karnataka.

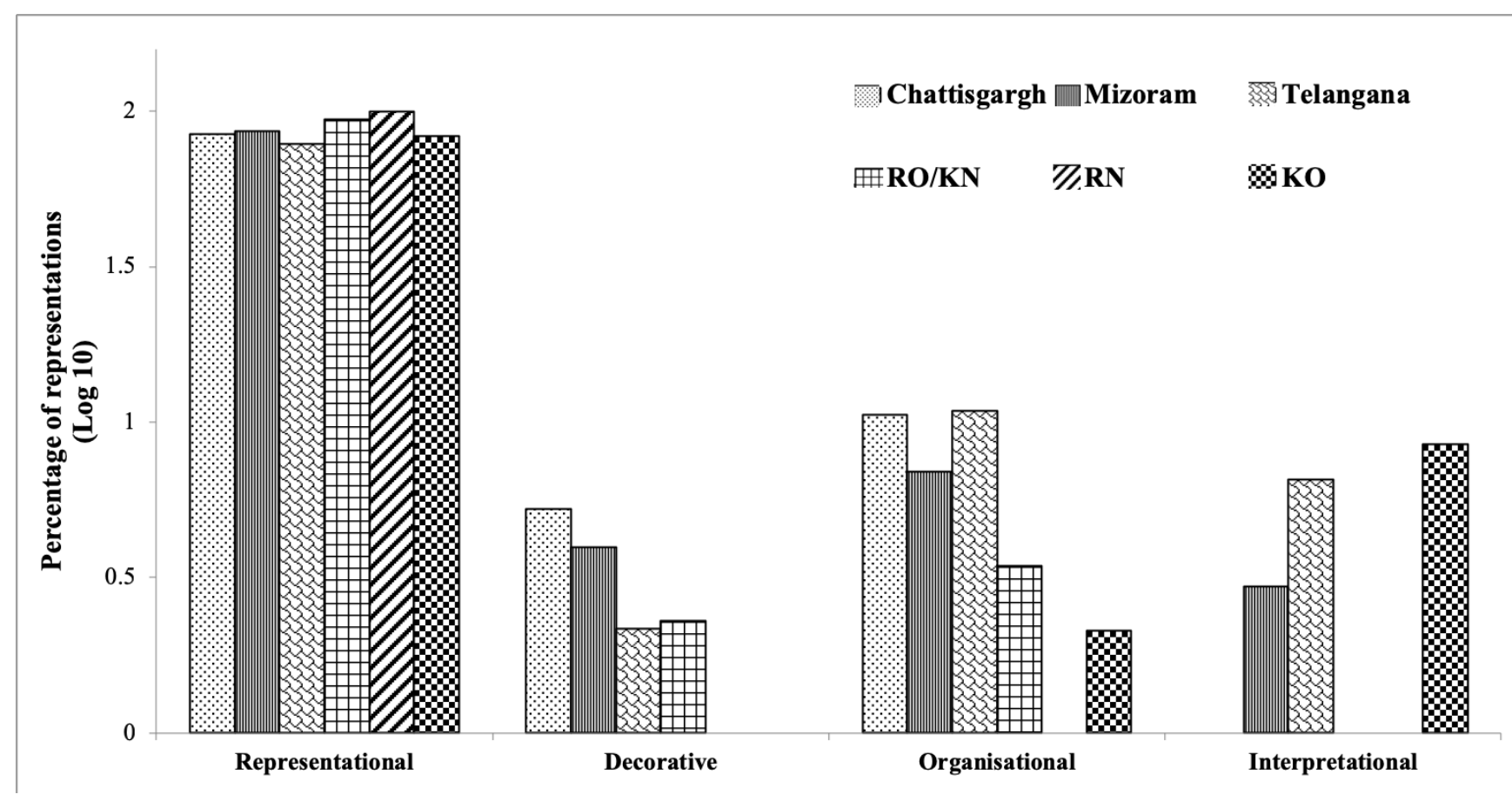


Figure 8 Conceptual integration of GRs present in the chapter on biodiversity and classification given in the IX ${ }^{\text {th }}$ standard biology textbook followed by five different states of India, Chhattisgarh, Mizoram, Telangana, Rajasthan and Karnataka.

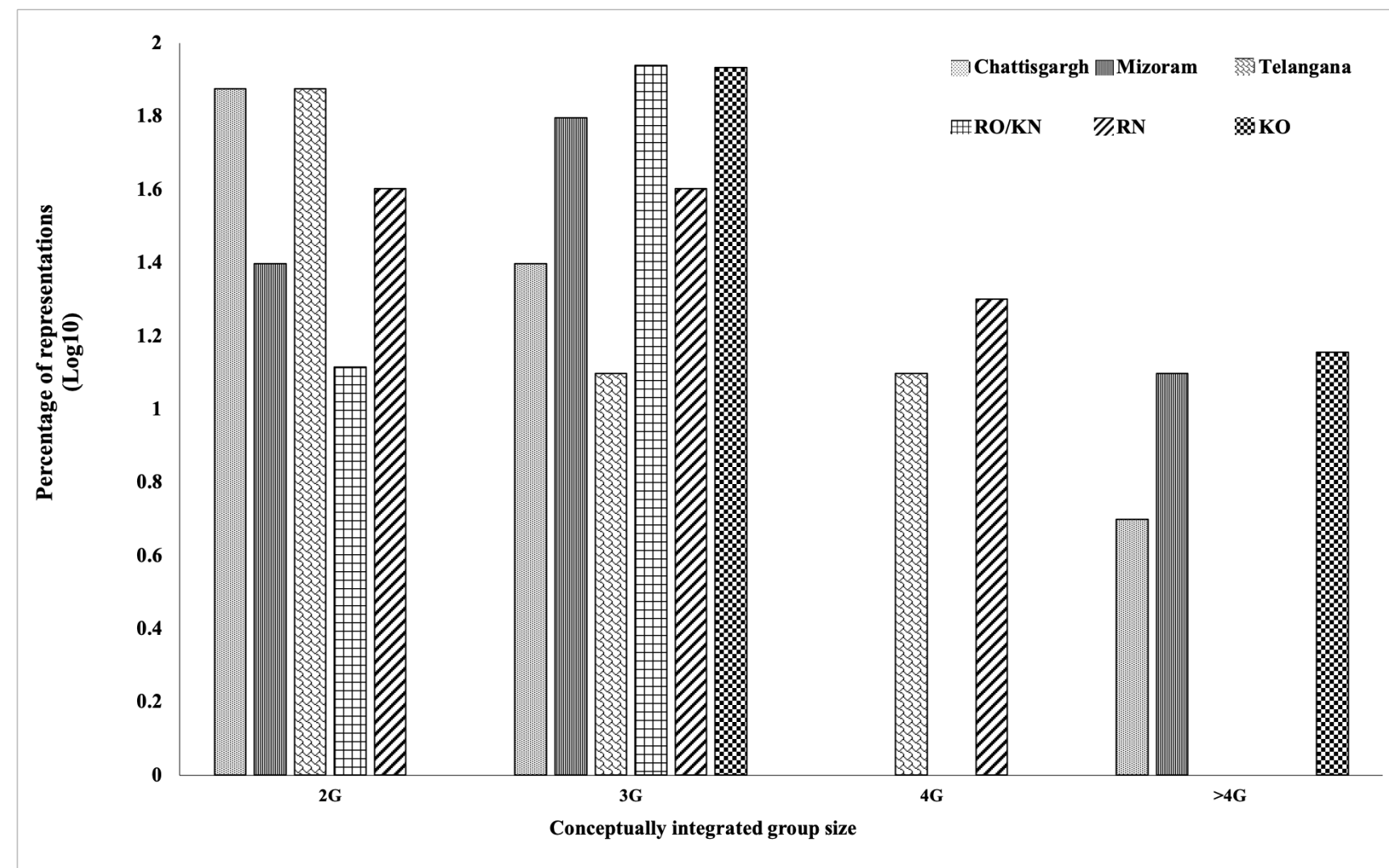


Figure 9 Conceptual interaction (CIn) of the GRs present in the chapter on biodiversity and classification given in the IX ${ }^{\text {th }}$ standard biology textbook followed by five different states of India, Chhattisgarh, Mizoram, Telangana, Rajasthan and Karnataka.

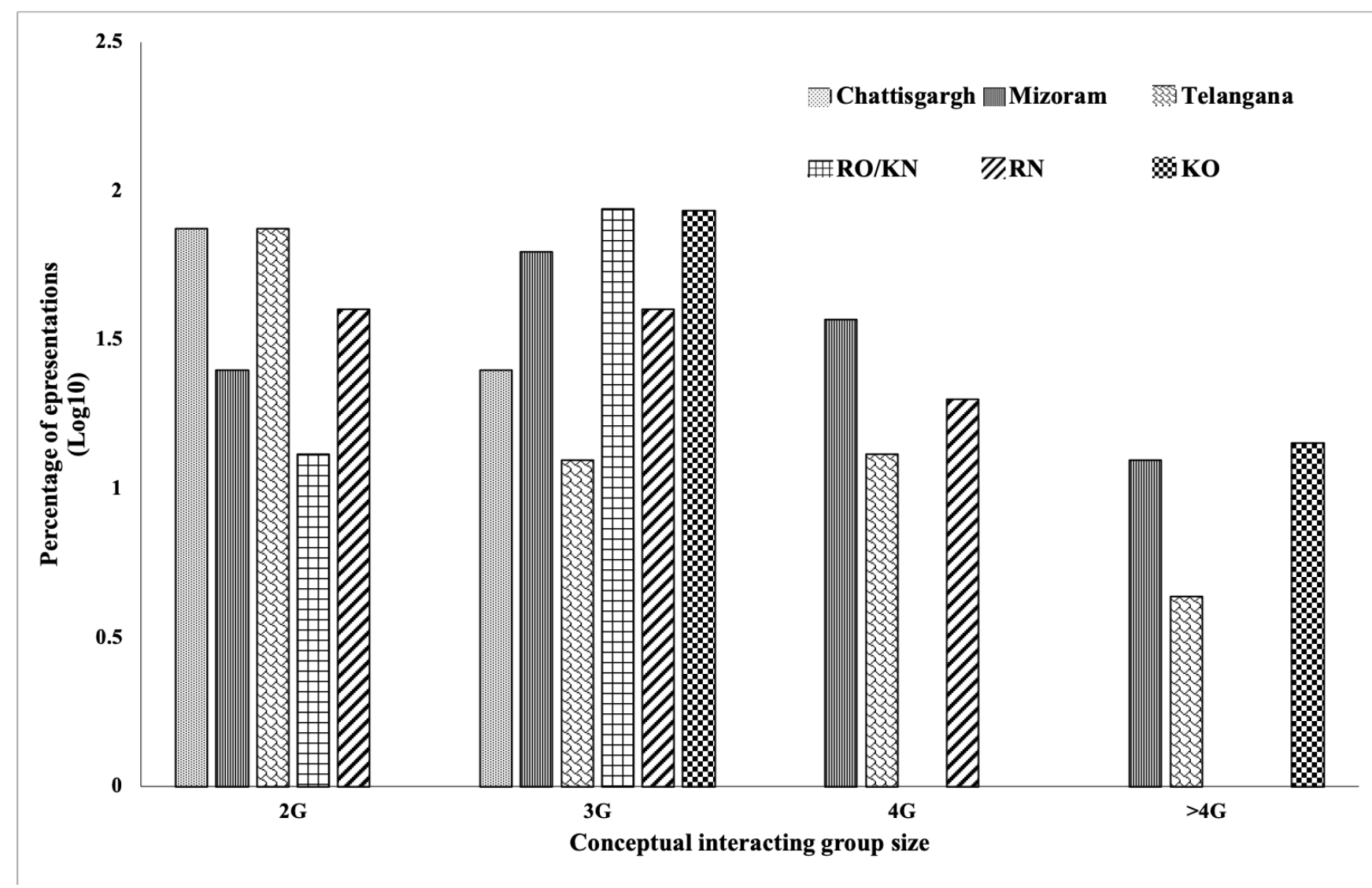

